\title{
Long-Run Underperformance And The Offering Price Clustering Phenomenon
}

Kevin C.H. Chiang, University of Vermont, USA

Harikumar Sankaran, New Mexico State University, USA

Xiyu (Thomas) Zhou, University of Alaska Fairbanks, USA

\begin{abstract}
The study proposes a new informational role for the offering price of an equity IPO. Offering prices are quoted either in whole prices (e.g., \$2, \$11, \$19, etc) or fractional prices (e.g., \$2.35, $\$ 11.15, \$ 15.75$, etc). Using Jay R. Ritter's sample of 1,526 IPOs issued during the period 1975 to 1984, the study examines the relation between the presence of whole price clusters and long-run underperformance. The results indicate that fractional offering prices are associated with better long-run performance.
\end{abstract}

Keywords: Initial public offerings; IPO offering price; Underperformance

\section{INTRODUCTION}

67

ffering prices are quoted either in whole prices (e.g., $\$ 2, \$ 11, \$ 19$, etc) or fractional prices (e.g., $\$ 2.35$, $\$ 11.15, \$ 15.75$, etc). Using Jay R. Ritter's sample of 1,526 IPOs issued during the period 1975 to 1984, we examine the relation between the presence of whole price clusters and long-run underperformance of equity IPOs. After controlling for other known variables, our findings indicate that fractional offering prices are associated with lower long-run underperformance.

A priori, one would not expect an informational role for offering prices. This is because, once the firm and their underwriters have estimated the total value of the IPO and have determined the fraction to sell, they have ample latitude in choosing any combination of number of shares and offering price. Despite the seemingly insignificant economic role played by the offering price, Chiang and Harikumar (2004) and Bradley, Cooney, Jordan, and Singh (2004) find that whole-priced IPOs are underpriced more relative to fractional-priced IPOs. ${ }^{1}$ In addition, Fernando, Krishnamurthy and Spindt (2002) document that low- and high-priced offers are associated with greater underpricing compared to medium-priced offers. The authors also find that offering prices are positively related to institutional ownership and that high-priced offers are more likely to outperform the low-priced offers during the five years after the IPO. ${ }^{2}$ These results suggest a potential informational role for offering price in explaining long-run performance of IPOs.

The study finds that IPOs with fractional offering prices do not underperform during the post-IPO period. ${ }^{3}$ Specifically, the average three-year buy-and-hold abnormal return for the sample of fractional-priced IPOs is positive regardless of the specification of the benchmark. In contrast, whole-priced IPOs seem to result in gradual but systematic underperformance in the aftermarket. Whole-priced IPOs also underperform under a variety of test specifications as well.

The rest of the paper is organized as follows: Section II describes the data, Section III empirically characterizes the relative long-run performance of whole- and fractional-priced IPOs, Section IV provides discussions, and some concluding remarks are contained in the final section. 


\section{DATA}

Jay R. Ritter (1991) provides the data used in this study. Our initial sample consists of 1,526 IPOs issued during the period 1975 to 1984 . The data only includes IPOs with an offering price of $\$ 1$ per share or more. Thus, the distribution of offering prices below $\$ 1$ is not observable. The range of offering prices in the data is from $\$ 1$ to $\$ 35$.

Daily aftermarket returns for these IPOs are retrieved from the 1997 Center for Research in Security Prices (CRSP) dataset. For IPOs that are delisted in the 36-month post-event window, we use the available return series and adjust for the delisting bias of Shumway (1997) and Shumway and Warther (1999) to mitigate survivorship bias. ${ }^{4}$ Shumway finds that most of the missing delisting returns in the CRSP tapes are associated with negative events and suggests a $-30 \%$ delisting monthly return for NYSE and AMEX stocks. Similarly, Shumway and Warther suggest a corrected delisting return of $-55 \%$ for NASDAQ stocks. Following their suggestions, we classify delisting codes 500 and 505 through 588 as negative-performance-related and adjust the data set for the missing delisting monthly returns with either $-30 \%$ or $-55 \%$.

We choose this data set for three reasons. First, it is relatively cleaner than alternative data sources (Ritter, 2000). Second, given the documented relationship between offering price clusters and underpricing with the use of this dataset by Chiang and Harikumar (2004), it would be interesting to see whether the economic significance of offering price clusters can be further enhanced by studying the relationship between offering price clusters and underperformance with the use of the same dataset. Third, by calendar year 1999, over $93 \%$ of all U.S. IPOs are priced at whole prices (Mola and Loughran, 2004). The use of an earlier dataset permits a more balanced analysis in which the results are not driven by relatively fewer fractional-priced IPOs.

\section{OFFERING PRICE CLUSTERING AND LONG-RUN PERFORMANCE}

The study calculates buy-and-hold abnormal returns (BHARs) and cumulative abnormal returns (CARs) based on the CRSP value-weighted index (VW), the CRSP equal-weighted index (EW), and the NASDAQ composite index (NASQ). ${ }^{5}$ The results are reported in Table 1.

Table1 reports three-year buy-and-hold abnormal returns (BHARs) and cumulative abnormal returns (CARs) for all, whole-priced, and fractional-priced IPOs with the following three benchmarks: the CRSP valueweighted index (VW), the CRSP equal-weighted index (EW), and the Nasdaq Composite index (NASQ). The full sample consists of 1,525 IPOs in which 1,056 IPOs are whole-priced and 469 IPOs are fractional-priced. BHARs and CARs are first aggregated across time, then across time. The t-test statistics are in parentheses.

Table 1: Abnormal Returns for All, Whole-Priced, and Fractional-Priced IPOs

\begin{tabular}{lcccccc}
\hline & \multicolumn{3}{c}{ BHAR } & \multicolumn{3}{c}{ CAR } \\
\cline { 2 - 7 } & VW & EW & NASQ & VW & EW & NASQ \\
\hline (1) All IPOs & -0.2276 & -0.2178 & -0.1028 & -0.2699 & -0.2626 & -0.1804 \\
& $(-6.12)^{*}$ & $(-5.94)^{*}$ & $(-2.74)^{*}$ & $(-9.86)^{*}$ & $(-9.73)^{*}$ & $(-6.52)^{*}$ \\
(2) Whole-Priced & -0.3333 & -0.3176 & -0.2112 & -0.3303 & -0.3190 & -0.2422 \\
IPOs & $(-8.59)^{*}$ & $(-8.24)^{*}$ & $(-5.39)^{*}$ & $(-10.05)^{*}$ & $(-9.86)^{*}$ & $(-7.29)^{*}$ \\
(3) Fractional- & 0.0105 & 0.0069 & 0.1414 & -0.1341 & -0.1335 & -0.0411 \\
Priced IPOs & $(0.13)$ & $(0.09)$ & $(1.70)$ & $(-2.74)^{*}$ & $(-2.80)^{*}$ & $(-0.83)$ \\
(3) - (2) & 0.3438 & 0.3246 & 0.3525 & 0.1962 & 0.1835 & 0.2011 \\
& $(4.29)^{*}$ & $(4.11)^{*}$ & $(4.36)^{*}$ & $(3.32)^{*}$ & $(3.15)^{*}$ & $(3.37)^{*}$ \\
\hline
\end{tabular}

* Significant at the $1 \%$ level

The average three-year BHARs for fractional-priced IPOs are 1.05\%, 0.69\%, and 14.14\% with the use of VW, EW, and NASQ, respectively. It is clear that based on this abnormal return metric, fractional-priced IPOs 
exhibit no long-run underperformance. In contrast, whole-priced IPOs show statistically significant underperformance. The $t$-statistics range from -5.39 to -8.59 . Based on average three-year BHARs, whole-priced IPOs underperform the various benchmarks by $21.12 \%$ to $33.33 \%$.

The study plots the time-series of BHARs in Figure 1, where BHARs are first aggregated across firms, then across time here. ${ }^{6}$ It is evident that fractional-priced IPOs outperform whole-priced IPOs across the whole range of the post-event window. The equality test reported in the last row of Table 1 summarizes the effects of offering price clustering on long-run performance. The BHARs of fractional-price IPOs are significantly higher than those of whole-priced IPOs at the $1 \%$ level of significance. The $t$-statistics range from 4.11 to 4.36 .

Figure 1: Series of Buy-and-Hold Abnormal Returns (BHARs) Net of the CRSP Value-Weighted Index for All, WholePriced, and Fractional-Priced IPOs, 1975-84

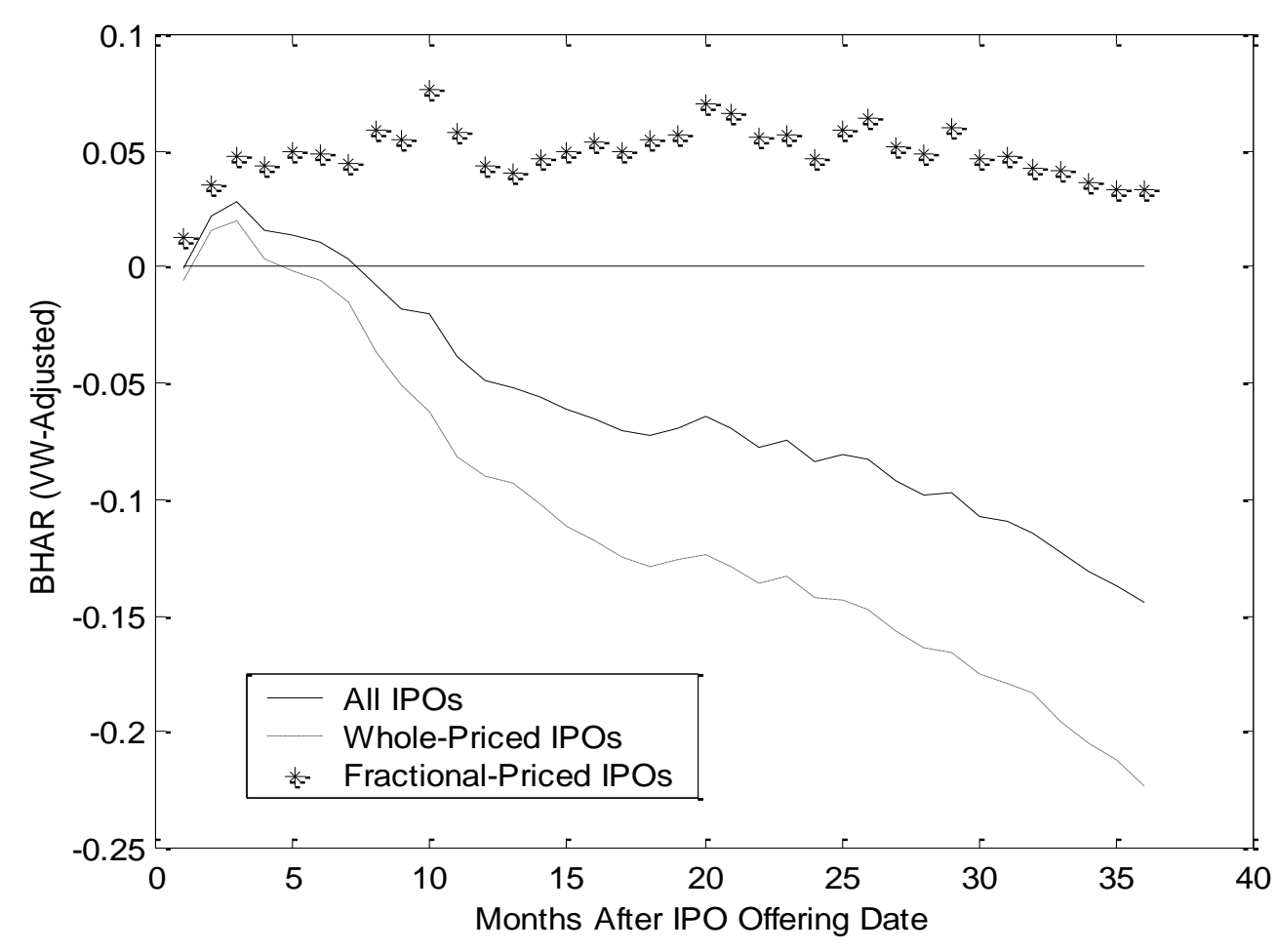

The full sample consists of 1,525 IPOs. The sample is then grouped into two sub-samples: 1,056 wholepriced IPOs and 469 fractional-priced IPOs. BHARs are first aggregated across time, then across firms.

The relative long-run performance between fractional- and whole-priced IPOs continues to hold when CARs are used. As presented in Table 1, the CARs of fractional-price IPOs are significantly higher than those of whole-priced IPOs at the $1 \%$ level of significance. The $t$-statistics range from 3.15 to 3.37. The time-series of CARs are presented in Figure 2. It is evident that the CARs of fractional-priced IPOs dominate those of wholepriced IPOs in the post-event window.

BHARs and CARs are intuitive metrics; however, they are not risk-adjusted in an equilibrium sense. The Fama-French three-factor model empirically identifies size and book-to-market as risk factors (Fama and French, 1993). The study uses the Fama-French three-factor calendar-time regression to investigate whether the differential performance between whole- and fractional-priced IPOs is simply due to the differences in exposures to market factor, size factor, and/or book-to-market factor between fractional- and whole-priced IPOs. 
Figure 2: Series of Cumulative Abnormal Returns (Cars) Net of the CRSP Value-Weighted Index for All, Whole-Priced, and Fractional-Priced IPOs, 1975-84

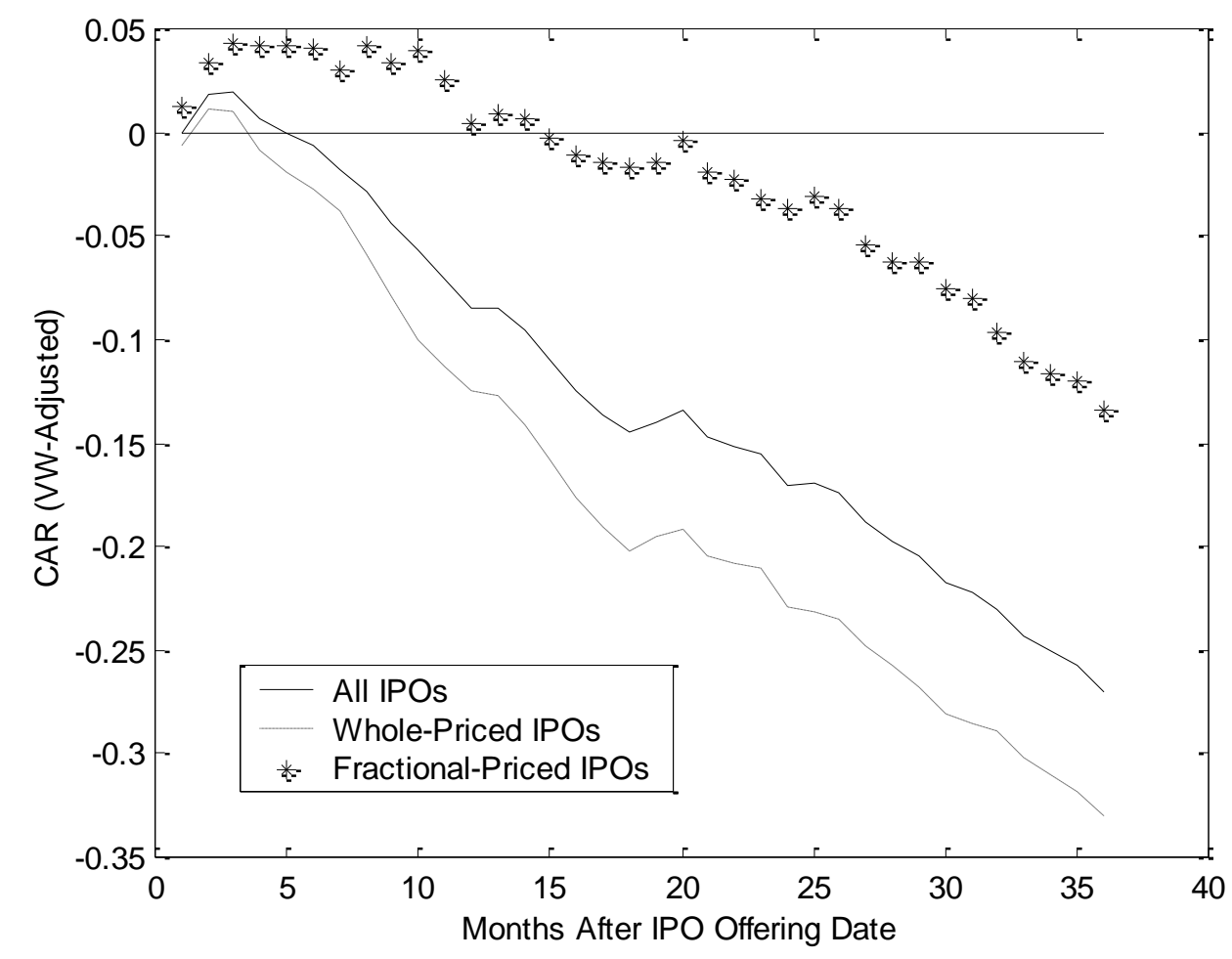

The full sample consists of 1,525 IPOs. The sample is then grouped into two sub-samples: 1,056 wholepriced IPOs and 469 fractional-priced IPOs. CARs are first aggregated across time, then across firms.

Table 2 reports the regression results. ${ }^{7}$ When equal weights are used, the intercept term for all IPOs has a value of -0.0049 . Consistent with the existing literature, the estimate is significant at the $10 \%$ level of significance with a $t$-statistic of -1.91 , suggesting that there is underperformance by the average firm. However, this underperformance virtually disappears when the same regression specification is applied to the portfolio of fractional-priced IPOs. The intercept term for fractional-priced IPOs is reduced more than by half and has a value of -0.0023 . This leads to a $t$-statistic of -0.75 that is not statistically significant at any conventional level. The analysis also shows that the underperformance documented for all IPOs are driven by the post-event returns of whole-priced IPOs. The intercept term for whole-priced IPOs has an estimate of -0.0062 with a $t$-statistic of -2.13 that is statistically significant at the 5\% level. To investigate whether the difference in performance between fractionaland whole-priced IPOs are statistically significant, the study uses the return differences between fractinal- and whole-priced IPOs as dependent variable and repeats the calendar-time regression. The difference in intercept terms of 0.0039 has a $t$-statistic of 1.29 that is not statistically significant at any conventional level. Overall, the equalweighted portfolio of fractional-priced IPOs generates higher returns than that of whole-priced IPOs by $0.39 \%$ ($0.0023+0.0062)$ per month after controlling for market beta, size and book-to-market. This leads to a better performance of $15.04 \%$ for fractional-priced IPOs in three years.

The calendar-time regression of Fama and French (1993) is specified as:

$r_{p, t}-r_{f, t}=\alpha_{p}+b_{p}\left[r_{m, t}-r_{f, t}\right]+s_{p} S M B_{t}+h_{p} H M L_{t}+\varepsilon_{p, t}$

where $r_{p, t}$ is either the equal-weighted or value-weighted portfolio return on IPOs, $r_{f, t}$ is the one-month Treasury bill 
rate, $r_{m, t}$ is the monthly return on the CRSP value-weighted index, $\mathrm{SMB}_{\mathrm{t}}$ is the difference between the returns on portfolios of small and big stocks, and $\mathrm{HML}_{t}$ is the difference between the returns on portfolios of high- and lowBE/ME (book-to-market ratio) stocks. All t-statistics are corrected using White's (1980) procedure and contained in parentheses.

Table 2: Calendar-Time Regressions of Equal-Weighted and Value-Weighted Monthly Returns on All, Whole-Priced, and Fractional-Priced IPOs with Market, Size, and Book-to-Market as Explanatory Variables

\begin{tabular}{|c|c|c|c|c|c|}
\hline & $\alpha_{p}$ & $b_{p}$ & $s_{p}$ & $h_{p}$ & $\begin{array}{c}\text { Adj. } \mathrm{R}^{2} \\
(\%)\end{array}$ \\
\hline \multicolumn{6}{|l|}{ Panel A: All IPOs } \\
\hline Equal-Weighted & $\begin{array}{l}-0.0049 \\
(-1.91) \diamond\end{array}$ & $\begin{array}{c}0.8736 \\
(12.11) *\end{array}$ & $\begin{array}{c}1.1824 \\
(12.16) *\end{array}$ & $\begin{array}{l}-0.4891 \\
(-3.84)\end{array}$ & 85.14 \\
\hline Value-Weighted & $\begin{array}{l}-0.0054 \\
(-2.39) \dagger\end{array}$ & $\begin{array}{c}0.8861 \\
(15.71) *\end{array}$ & $\begin{array}{c}1.1803 \\
(13.85) *\end{array}$ & $\begin{array}{l}-0.5709 \\
(-5.39) *\end{array}$ & 87.73 \\
\hline \multicolumn{6}{|c|}{ Panel B: Whole-Priced IPOs } \\
\hline Equal-Weighted & $\begin{array}{c}-0.0062 \\
(-2.13) \dagger\end{array}$ & $\begin{array}{c}0.8737 \\
(11.00) *\end{array}$ & $\begin{array}{c}1.1748 \\
(10.04) *\end{array}$ & $\begin{array}{c}-0.5247 \\
(-4.32)\end{array}$ & 80.35 \\
\hline Value-Weighted & $\begin{array}{c}-0.0069 \\
(-2.91) *\end{array}$ & $\begin{array}{c}0.8918 \\
(17.26) *\end{array}$ & $\begin{array}{c}1.1916 \\
(13.48) *\end{array}$ & $\begin{array}{l}-0.6127 \\
(-6.21)\end{array}$ & 85.37 \\
\hline \multicolumn{6}{|c|}{ Panel C: Fractional-Priced IPOs } \\
\hline Equal-Weighted & $\begin{array}{c}-0.0023 \\
(-0.75)\end{array}$ & $\begin{array}{c}0.8687 \\
(10.97) *\end{array}$ & $\begin{array}{c}1.1904 \\
(10.32) *\end{array}$ & $\begin{array}{c}-0.4331 \\
(-2.63) *\end{array}$ & 80.31 \\
\hline Value-Weighted & $\begin{array}{c}-0.0019 \\
(-0.61)\end{array}$ & $\begin{array}{c}0.8617 \\
(10.20)\end{array}$ & $\begin{array}{c}1.1661 \\
(9.41) *\end{array}$ & $\begin{array}{l}-0.4987 \\
(-3.24) *\end{array}$ & 80.05 \\
\hline \multicolumn{6}{|c|}{ Panel D: Fractional-Priced IPOs - Whole-Priced IPOs } \\
\hline Equal-Weighted & $\begin{array}{c}0.0039 \\
(1.29)\end{array}$ & $\begin{array}{c}-0.0050 \\
(-0.07)\end{array}$ & $\begin{array}{l}0.0157 \\
(0.12)\end{array}$ & $\begin{array}{l}0.0915 \\
(0.80)\end{array}$ & -0.01 \\
\hline Value-Weighted & $\begin{array}{c}0.0051 \\
(1.73) \diamond\end{array}$ & $\begin{array}{c}-0.0301 \\
(-0.46)\end{array}$ & $\begin{array}{c}-0.0255 \\
(-0.22)\end{array}$ & $\begin{array}{c}0.1141 \\
(0.97)\end{array}$ & 0.00 \\
\hline
\end{tabular}

$\triangle$ Significant at the $10 \%$ level

$\uparrow$ Significant at the $5 \%$ level

*Significant at the $1 \%$ level

When value weights are used, the difference in performance between fractional- and whole-priced IPOs is more evident. The intercept estimate for fractional-priced IPOs is -0.0019 . The $t$-statistic of -0.61 is not statistically significant at any conventional level. In contrast, the intercept terms for all IPOs and whole-priced IPOs yield tstatistics of -2.39 and -2.91 that are statistically significant at the $5 \%$ level and the $1 \%$ level, respectively. The difference in intercept terms of 0.0051 has a $t$-statistic of 1.73 that is statistically significant at the $10 \%$ level. Overall, the value-weighted portfolio of fractional-priced IPOs generates higher returns than that of whole-priced IPOs by $0.51 \%$ per month. This leads to a superior performance of $20.10 \%$ for fractional-priced IPOs in three years. ${ }^{8}$

Having shown that under a variety of testing specifications, fractional-priced IPOs do not exhibit long-run underperformance, the study turns its attention to the robustness of the results. Specifically, the study examines the relationship between offering price clusters and long-term abnormal performance when other known variables are considered as part of multivariate OLS regressions. Dependent variables include the natural logarithm of $1,000 \%$ plus individual BHARs and individual CARs. ${ }^{9}$ The selection of independent variables is largely an extension of that specified in Carter, Dark, and Singh (1998). These control variables include the natural log of the proceeds of the issue (PROCEEDS), the issuer's age at the offering date (AGE), offering as a fraction of shares to be outstanding (OF), three-year aftermarket standard deviation (STD), and the Carter and Manaster (1990) reputation ranking (CM). Our focus is the explanatory ability of the binary variable of CLUSTER that takes a value of one for wholepriced IPOs and zero for fractional-priced IPOs on long-run abnormal returns.

The regression results are presented in Table 3. All the univariate regressions indicate that CLUSTER is statistically and economically significant in explaining long-run performance. The $t$-statistics range from -3.16 to - 
4.07 that are all statistically significant at the $1 \%$ level. These results are robust to the addition of control variables. The $t$-statistics for CLUSTER in multivariate regressions range from -1.97 to -2.82 . They are at least statistically significant at the 5\% level. In short, the explanatory ability of CLUSTER is robust under a variety of performance metrics.

OLS Regressions Are Used To Examine The Determinants Of IPO Three-Year Post-IPO Abnormal Returns. The dependent variables are either (1) the natural $\log$ of $100 \%$ plus buy-and-hold abnormal returns (BHARs) or (2) cumulative abnormal returns (CARs). The calculation of BHARs and CARs are based on three different benchmarks: the CRSP value-weighted index (VW), the CRSP equal-weighted index (EW), and the Nasdaq Composite index (NASQ). The independent variables include a binary variable that takes a value of one for whole-priced IPOs and zero for fractional-priced IPOs (CLUSTER), the natural log of the size of proceeds (PROCEEDS), the natural log of one plus firm age (AGE), offering as a fraction of shares to be outstanding (OF), post-IPO standard deviation (STD), and the Carter and Manaster's (1990) reputation measure (CM). All t-statistics are corrected for heteroskedasticity using White's (1980) procedure and contained in parentheses.

Table 3: OLS Testing Results of Six Explanatory Variables on IPO Long-Run Performance

\begin{tabular}{|c|c|c|c|c|c|c|c|c|}
\hline & Intercept & CLUSTER & PROCEEDS & AGE & $\mathrm{OF}$ & STD & $\mathrm{CM}$ & $\begin{array}{c}\text { Adj. } \mathrm{R}^{2} \\
(\%)\end{array}$ \\
\hline \multicolumn{9}{|c|}{ Panel A. $\log (1000 \%+$ BHARs $)$} \\
\hline \multirow{2}{*}{ VW } & 2.2918 & $\begin{array}{l}-0.0303 \\
(-3.99) *\end{array}$ & & & & & & 1.16 \\
\hline & 2.5116 & $\begin{array}{l}-0.0207 \\
(-2.75) *\end{array}$ & $\begin{array}{l}-0.0081 \\
(-2.12) \dagger\end{array}$ & $\begin{array}{l}-0.0293 \\
(-6.24)^{*}\end{array}$ & $\begin{array}{c}0.0471 \\
(2.02) \dagger\end{array}$ & $\begin{array}{l}-0.1703 \\
(-3.91)^{*}\end{array}$ & $\begin{array}{l}0.0067 \\
(4.33)^{*}\end{array}$ & 7.51 \\
\hline \multirow[t]{2}{*}{ EW } & 2.2917 & $\begin{array}{l}-0.0285 \\
(-3.78)^{*}\end{array}$ & & & & & & 1.03 \\
\hline & 2.3641 & $\begin{array}{l}-0.0191 \\
(-2.56) \dagger\end{array}$ & $\begin{array}{c}0.0004 \\
(0.11) \\
\end{array}$ & $\begin{array}{l}-0.0252 \\
(-4.82)^{*}\end{array}$ & $\begin{array}{c}0.0588 \\
(2.51) \dagger \\
\end{array}$ & $\begin{array}{l}-0.1813 \\
(-4.19)^{*} \\
\end{array}$ & $\begin{array}{l}0.0056 \\
(3.72)^{*}\end{array}$ & 7.75 \\
\hline \multirow[t]{2}{*}{ NASQ } & 2.3048 & $\begin{array}{l}-0.0308 \\
(-4.07)^{*}\end{array}$ & & & & & & 1.21 \\
\hline & 2.5442 & $\begin{array}{l}-0.0212 \\
(-2.82)^{*}\end{array}$ & $\begin{array}{l}-0.0093 \\
(-2.42) \dagger\end{array}$ & $\begin{array}{l}-0.0298 \\
(-6.42)^{*}\end{array}$ & $\begin{array}{c}0.0426 \\
(1.84)\end{array}$ & $\begin{array}{l}-0.1620 \\
(-3.77)^{*}\end{array}$ & $\begin{array}{l}0.0072 \\
(4.59)^{*}\end{array}$ & 7.59 \\
\hline \multicolumn{9}{|c|}{ Panel B. CARs } \\
\hline \multirow[t]{2}{*}{ VW } & & $\begin{array}{l}-0.1962 \\
(-3.33)^{*}\end{array}$ & & & & & & 0.65 \\
\hline & 1.1383 & $\begin{array}{l}-0.1374 \\
(-2.35) \dagger\end{array}$ & $\begin{array}{c}-0.0480 \\
(-1.45)\end{array}$ & $\begin{array}{l}-0.2359 \\
(-8.25)^{*}\end{array}$ & $\begin{array}{c}0.3460 \\
(1.59)\end{array}$ & $\begin{array}{c}0.0062 \\
(0.01) \\
\end{array}$ & $\begin{array}{l}0.0576 \\
(4.00)^{*}\end{array}$ & 4.48 \\
\hline \multirow[t]{2}{*}{ EW } & -0.1355 & $\begin{array}{l}-0.1835 \\
(-3.12)^{*}\end{array}$ & & & & & & 0.58 \\
\hline & 0.2361 & $\begin{array}{l}-0.1247 \\
(-2.17) \dagger\end{array}$ & $\begin{array}{c}0.0061 \\
(0.19) \\
\end{array}$ & $\begin{array}{l}-0.2180 \\
(-7.03)^{*}\end{array}$ & $\begin{array}{c}0.4218 \\
(1.95)\end{array}$ & $\begin{array}{c}-0.0748 \\
(-0.17)\end{array}$ & $\begin{array}{l}0.0501 \\
(3.54)^{*}\end{array}$ & 4.70 \\
\hline \multirow[t]{2}{*}{ NASQ } & -0.0411 & $\begin{array}{l}-0.2012 \\
(-3.38)^{*}\end{array}$ & & & & & & 0.67 \\
\hline & 1.4186 & $\begin{array}{l}-0.1417 \\
(-2.39) \dagger\end{array}$ & $\begin{array}{c}-0.0595 \\
(-1.78)\end{array}$ & $\begin{array}{l}-0.2420 \\
(-8.41)^{*}\end{array}$ & $\begin{array}{c}0.3167 \\
(1.44)\end{array}$ & $\begin{array}{c}0.0625 \\
(0.14)\end{array}$ & $\begin{array}{l}0.0613 \\
(4.21)^{*}\end{array}$ & 4.55 \\
\hline
\end{tabular}

$\uparrow$ Significant at the 5\% level

*Significant at the $1 \%$ level

\section{DISCUSSION}

Admittedly, clustering per se is unlikely to be the source of underpricing and underperformance. Then, what might explain the documented relationship between offering price clusters and long-run performance?

A seemingly apparent explanation is that investment bankers use fractional offering prices when they engage in costly information production. ${ }^{10}$ The choice of information production efforts is consistent with the dynamic game model in Chennanur and Fulghieri (1994) where information asymmetry is mitigated through 
reputation acquisition by underwriters' certifications on issuers' projects. ${ }^{11}$ The notion of reputation, therefore, can be related to the probability of underpricing as emphasized in their model, to the probability of underperformance as argued in Carter, Dark, and Singh (1998), or to some combination of the two probabilities if underwriters view both large underpricing and severe underperformance undesirable. To investigate whether reputation acquisition is empirically relevant, the study examines the effects of underwriters' reputation and offering price clusters on underpricing and underperformance. Figure 3 presents average initial returns and BHARs for four sub-samples using two cutoff criteria: (1) whether an IPO's Carter and Manaster (1990) reputation ranking is less or no less than six, ${ }^{12}$ and (2) whether the IPO is whole- or fractional-priced. The figure shows that fractional-priced IPOs that are marketed by underwriters with relatively lower reputation do as well as IPOs that are marketed by reputable underwriters in terms of both initial returns and three-year BHARs. ${ }^{13}$

Figure 3: The Effects of Underwriters' Reputation and Offering Price Clusters on Initial Returns and Three-Year Abnormal Buy-and-Hold Returns (BHARS)

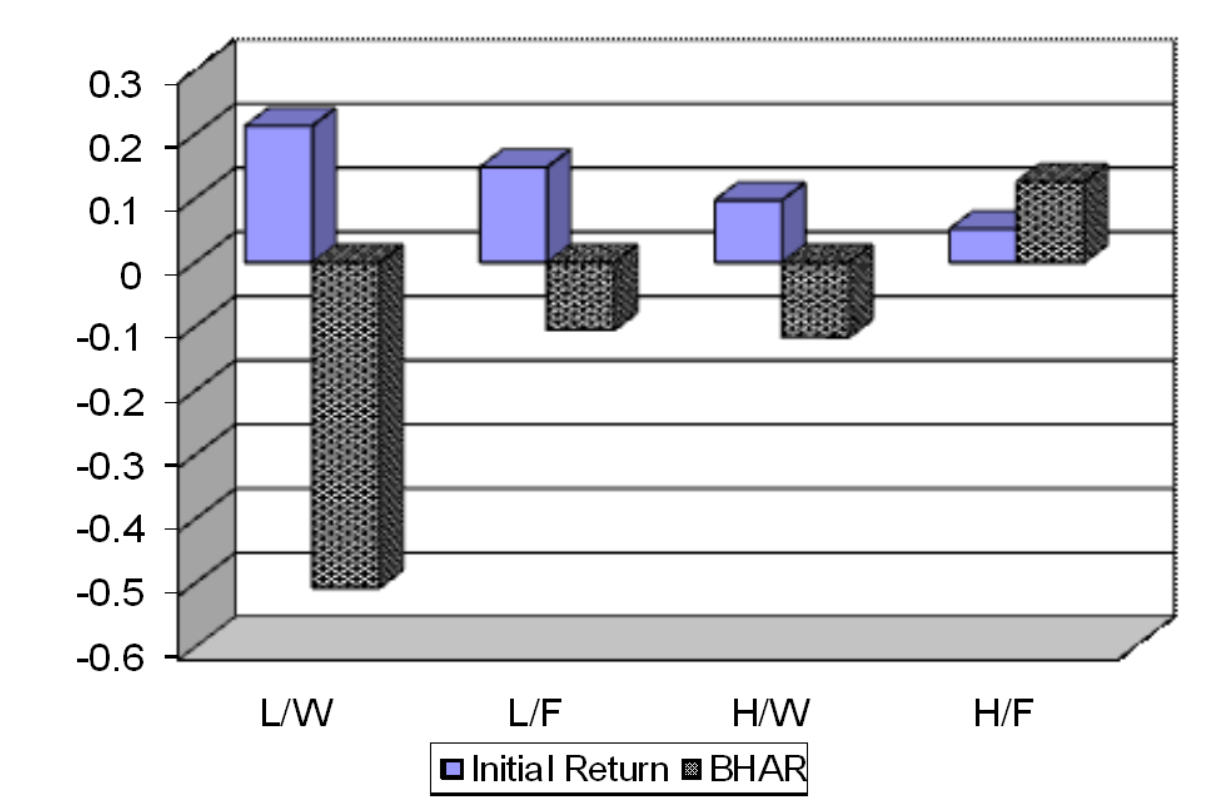

The full sample of 1,525 IPOs are grouped into four portfolios based on two criteria: (1) whether they are marketed by underwriters who have a Carter and Manaster (1990) reputation ranking less than 6 (L) or no less than $6(\mathrm{H})$, and (2) whether they are whole-priced (W) or fractional-priced (F).

A caveat is in order. While the reputation acquisition explanation is capable of explaining why there might be less underpricing for fractional-priced IPOs, this explanation cannot fully explain the relationship between offering price clusters and long-run performance on a rational basis. The reason for this is that in an efficient market investors should be able quickly price IPOs to fully reflect their intrinsic values. Unless clustering plays a behavioral role, there should be no relationship between offering price clusters and long-run performance.

\section{CONCLUSION}

Offering prices has an informational role. The existing literature shows that fractional-priced IPOs have less underpricing. This study finds that offering price clusters also has an impact on long-run performance. Under a variety of testing specifications, fractional-priced IPOs do not exhibit long-run underperformance. The documented underperformance is mainly driven by whole-priced IPOs. 
This study is empirical and exploratory. While the study provides some discussions about a plausible explanation, it comes short of presenting an economic reason for the documented results. We believe that this puzzling regularity requires new explanations and leaves them to be explored by future research.

\section{ACKNOWLEDGEMENT}

We wish to thank Jay R. Ritter for his data and comments.

\section{AUTHOR INFORMATION}

Kevin Chiang is Associate Professor of Finance, University of Vermont, PhD Finance, Louisiana State University 2000 and has taught at University of Alaska, Fairbanks; Northern Arizona University before joining U. Vermont. Has published on Accounting and Finance, Journal of Real Estate Research, Real Estate Economics, Journal of Real Estate Finance and Economics, Journal of Investing, Journal of Financial Intermediation, among others.

Harikumar Sankaran is Associate Professor of Finance, New Mexico State University, PhD Finance, University of Houston and has taught at University of Miami (Florida), University of Alaska, Fairbanks before joining NMSU. Has published on Review of Quantitative Finance and Accounting, Managerial Decision Economics, Journal of Financial Research, Quarterly Review of Economics and Finance, among others.

Xiyu (Thomas) Zhou is Assistant Professor of Finance, University of Alaska, Fairbanks, PhD Finance, UNCChapel Hill, 2004 and has taught at UNC-Chapel Hill, Duke University, before joining University of Alaska, Fairbanks. Has published on Accounting and Finance, Journal of Investing, Corporate Finance Review, among others.

\section{REFERENCES}

1. Bradley, D., Cooney, J. Jr., Jordan, B., and Singh, A.K. (2004) Negotiation and the IPO offer price: a comparison of interger versus non-integer IPOs, Journal of Financial and Quantitative Analysis, 39, 517 540.

2. Carter, R.B., Dark, F.H., and Singh, A.K. (1998) Underwriter reputation, initial returns, and the long-run performance of IPO stocks, Journal of Finance, 53, 285-311.

3. Carter, R.B., and Manaster, S. (1990) Initial public offerings and underwriter reputation, Journal of Finance, 45, 1045-1067.

4. Chemmanur, T.J., and Fulghieri, P. (1994) Investment bank reputation, information production, and financial intermediation, Journal of Finance, 49, 57-79.

5. Chiang, K., and Harikumar T. (2004) Offering price clusters and underpricing in the US primary market, Applied Financial Economics, 14, 809-822.

6. Fama, E.F. (1998) Market efficiency, long-term returns, and behavioral finance, Journal of Financial Economics, 49, 283-306.

7. Fama, E.F., and French, K.R. (1993) Common risk factors in the returns on stocks and bonds, Journal of Financial Economics, 33, 3-56.

8. Fernando, C.S., Krishnamurthy, S., and Spindt, P.A. (2002) Is the offer price in IPOs informative? underpricing, ownership structure, and performance, Working paper, University of Michigan.

9. Loughran, T., and Ritter, J.R. (1995) The new issues puzzle, Journal of Finance, 50, 23-51.

10. Loughran, T., and Ritter, J.R. (2000) Uniformly least powerful tests of market efficiency, Journal of Financial Economics, 55, 361-389.

11. Mola, S., and Loughran T. (2004) Discounting and clustering in seasoned equity offering prices, Journal of Financial and Quantitative Analysis, 39, 1-24.

12. Ritter, J.R. (1991) The long-run performance of initial public offerings, Journal of Finance, 46, 3-27.

13. Ritter, J.R. (2000) SDC (Securities Data Co.) corrections from Jay R. Ritter, Unpublished note, University of Florida.

14. Shumway, T.G. (1997) The delisting bias in CRSP data, Journal of Finance, 52, 327-340. 
15. Shumway, T.G., and Warther, V.A. (1999) The delisting bias in CRSP's Nasdaq data and its implication for the size effect, Journal of Finance, 54, 2361-2379.

16. Stern, R.L., and Bornstein, P. (1985) Why new issues are lousy investments, Forbes, 136, 152-190.

17. Stoll, H.R., and Curley, A,J, (1970) Small business and the new issues market for equities, Journal of Financial and Quantitative Analysis, 5, 309-322.

18. ${ }^{14}$ White, H. (1980) A heteroskedasticity-consistent covariance matrix estimator and a direct test for heteroskedasticity, Econometrica, 22, 817-838.

\footnotetext{
${ }^{1}$ Mola and Loughran (2004) find whole-priced seasoned equity offers are associated with larger discounts.

2 These authors compare offering prices to stock split announcements. In the latter case, one would not expect a market reaction because it is merely an accounting adjustment. However, there exists a vast literature that documents and analyzes the market reaction to stock split announcements.

${ }^{3}$ See Stoll and Curley (1970), Stern and Borstein (1985), Ritter (1991), and Loughran and Ritter (1995, 2000) for the underperformance of IPOs.

${ }^{4}$ One of Ritter's (1991) sample firms, whose CRSP permanent number is 11077, is excluded for the study of long-run returns because it has no return observations in the 1997 CRSP daily files.

${ }^{5}$ It is well known that BHARs tend to cause inference problems (e.g., Fama, 1998). Therefore, the absolute levels of BHARs need to be interpreted with caution. However, our analysis is primarily to compare the relative performance between fractionaland whole-priced IPOs. So long as inference problems affect both fractional- and whole-priced IPOs in a similar manner, these problems are controlled to some degree in our investigation.

${ }^{6}$ The plotted values are net of VW. The results are quite similar when other benchmarks are used.

${ }^{7}$ The regression analyses are based on IPO returns between June 1975 and December 1987 . The returns between January 1975 and May 1975 are excluded from the analyses because too few whole-priced IPOs are available for forming a portfolio.

${ }^{8}$ Note that, unlike those used in Loughran and Ritter (2000), the factor series used in this study are not purged of new issues. Because IPOs are part of the construction of regressors, the resulting lower power may cause inference problems. However, again, the primary objective of this study is to examine the relative performance between fractional- and whole-priced IPOs. Presumably, these problems are controlled to some degree when fractional- and whole-priced IPOs are compared on a relative basis. Therefore, our results should sustain even when new issues are purged from regressors.

${ }^{9}$ Following Carter, Dark, and Singh (1998), we shift the BHARs by $1000 \%$ and then take natural logarithm of the sum to mitigate BHARs' skewness problem. We also run regressions with BHARs without the transformation, the results are similar. No transformation is used for CARs because their distributions are closer to normal.

${ }^{10}$ Whole-priced (fractional-priced) IPOs are generated from a coarser (finer) set of prices. Holding other factors constant, the price discovery of whole prices, on average, requires a lower degree of information production than that of fractional prices.

${ }^{11}$ An important feature of the model is that there are two types of underwriters: (1) no-variable-cost underwriters who have a special expertise in evaluating firms by which they only need to incur fixed evaluation cost, and (2) high-cost underwriters who need to incur variable evaluation cost if they set strict evaluation standards. The resulting dynamic equilibrium predicts that novariable-cost underwriters will always adopt strict evaluation standards to protect their reputation, while high-cost underwriters may adopt strict, thus costly, evaluation standards if they want to gain reputation and higher future fees. As long as some highcost underwriters choose not to adopt strict evaluation standards, we expect that offering prices cluster at whole prices because the price discovery of whole prices, on average, requires a lower degree of information production. In addition, reputation in this equilibrium reflects an investor's probability assessment of an underwriter being of the no-variable-cost type because the investor knows that no-variable-cost type has a stronger incentive to set strict standards. Thus, on average, no-variable-cost underwriters tend to be reputable underwriters, while high-cost tend to be less reputable underwriters.

12 The mean reputation ranking for the full sample is 5.4.

${ }^{13}$ The results are similar when CARs are used.
} 


\section{NOTES}

